\title{
The Prevalence and Morphology of Cataract in Patients on Allopurinol Treatment
}

\author{
C. S. C. LIU, ${ }^{*}$ N. A. P. BROWN, ${ }^{* *}$ T. J. K. LEONARD, ${ }^{*}$ P. W. BULL, ${ }^{*}$ J. T. SCOTT* \\ London and Oxford
}

\begin{abstract}
Summary
We have shown that an unusual morphological thinning of the anterior clear zone of the lens is found in patients with gout on long term Allopurinol therapy. The significance of this is discussed.
\end{abstract}

Allopurinol is an anti-hyperuricaemic drug widely used for the treatment of gout. 1,2

In 1982, Fraunfelder et al reported 30 cases of cataracts associated with chronic Allopurinol ingestion. ${ }^{3}$ Whereas six of these cases had previously been reported, the other 24 had been accumulated by the National Registry of Drug Induced Ocular Side Effects, Portland, Oregan, U.S.A. Concurrently, Lerman, Megaw and Gardner ${ }^{4}$ were able to demonstrate in vitro the probable presence of Allopurinol in cataractous lenses extracted from patients on Allopurinol by phosphorescene techniques. There characteristic phosphorescence peaks were neither present in cataractous lenses extracted from patients not ingesting Allopurinol nor in non-cataractous lenses from deceased patients who had been on long term Allopurinol therapy. ${ }^{5}$

Ultraviolet radiation, even at ambient levels, was implicated in photobinding Allopurinol permanently to lens proteins. It is thought that the bound Allopurinol absorbs the near ultraviolet radiation which is transmitted through the cornea, thereby enhancing the "normal, actinic, ageing" process in the lens.

Animal studies support the theory of photobinding. ${ }^{4}$ Sprague-Dawley white rats given Allopurinol intraperitoneally yielded lenses which amit the Allopurinol phosphorescent peak 24 hours after the injection provided these rats were exposed to ultraviolet light in vivo. Those rats kept in the dark after the injection when sacrificed after 24 hours yielded lenses which do not emit this peal. The characteristic peak was however present if the rats were sacrificed at two hours after the injection. This peak falls progressively until none could be demonstrated at 18 hours post injection in rats kept in the dark.

In this country, we wonder whether Allopurinol might be less cataractogenic in view of the lower level of ultraviolet radiation compared with most parts of the United States of America. The total annual sunshine in Kew is 1514 hours in contrast to annual figures of 2044 hours in Seattle and going up to 3348 hours in Los Angeles.

Whereas gout in itself has not been reported to be cataractogenic, we set out to study the prevalence of cataract in a group of patients on Allopurinol treatment.

\section{Method}

The population studied are patients attending the gout clinic at Charing Cross Hospital, London. Sixty three patients were invited to attend the eye clinic for ocular examination. Of these, 53 patients agreed.

From *The Charing Cross Hospital, London.

** Nuffield Laboratory of Ophthalmology, Oxford. 
Table I Age histogram of population studied

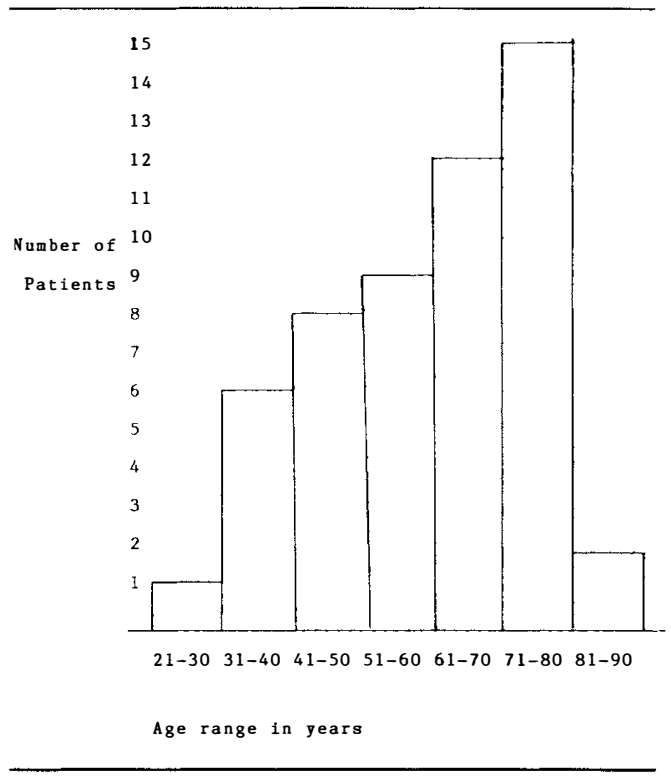

Table II Length of Allopurinol Ingestion

\begin{tabular}{lcccc}
\hline $\begin{array}{l}\text { Length of } \\
\text { Ingestion }\end{array}$ & $\begin{array}{c}2 \\
\text { years }\end{array}$ & $\begin{array}{c}2-5 \\
\text { years }\end{array}$ & $\begin{array}{c}6-10 \\
\text { years }\end{array}$ & $\begin{array}{c}\text { over 10 } \\
\text { years }\end{array}$ \\
$\begin{array}{l}\text { Number of } \\
\text { patients }\end{array}$ & 7 & 21 & 11 & 14 \\
\hline
\end{tabular}

The age of these patients ranged between 29 and 89 years. The mean age was 59.45 years (Table I). All the patients were male. All the patients, except three, had been on Allopurinol for 18 months or more in a usual dose of $300 \mathrm{mg}$ daily. (Table II). All patients, except three, were Caucasians.

Patients were asked about factors which might have predisposed cataract formation. ${ }^{6}$ There included diabetes mellitus, cardiovascular disease, renal failure, ${ }^{1}$ severe life threatening dehydration episodes, a positive family history and known radiation exposure. A drug history was taken and particular attention was drawn to the use of steroids (topical and systemic), nifedipine and painkillers (non steroidal antiinflammatory drugs and paracetamol).

A full, past ophthalmic history was taken including details of ocular surgery, trauma, glaucoma and antiglaucoma therapy, especially pilocarpine drops, uveitis, keratitis and myopia.

The patient's occupation during the period of ingestion of Allopurinol was noted so as to judge to what extent they had been exposed to ambient as well as artificial ultraviolet radiation.

Patients were then examined with the slit

Table III Overall results

Number of eyes with a particular graded feature

\begin{tabular}{|c|c|c|c|c|c|c|c|c|c|c|}
\hline \multicolumn{11}{|l|}{ Class } \\
\hline 0 & 1 & 89 & 55 & 88 & 61 & 72 & 91 & 32 & 3 & N/A \\
\hline I & 25 & $9^{*}$ & 36 & 13 & 42 & 21 & 10 & 31 & 48 & 0 \\
\hline II & 27 & 1 & 10 & 1 & 1 & 6 & 0 & 22 & 48 & 13 \\
\hline III & 41 & 2 & 1 & 0 & 0 & 1 & 1 & 14 & 3 & 28 \\
\hline IV & 9 & 0 & 0 & 0 & 0 & 1 & 0 & 5 & 0 & 24 \\
\hline V & 1 & 0 & 0 & 0 & 0 & 0 & 0 & 0 & 0 & 37 \\
\hline$?$ & $\begin{array}{c}0 \\
(\mathrm{O} \& \mathrm{I})\end{array}$ & 2 & $2 \dagger$ & 2 & 0 & 3 & 2 & 0 & $\begin{array}{c}2 \\
(\mathrm{II}-\mathrm{V})\end{array}$ & 2 \\
\hline Cumulative & 26 & 12 & 47 & 14 & 43 & 29 & 11 & 72 & 51 & N/A \\
\hline Total & 104 & $103^{*}$ & 104 & 104 & 104 & 104 & 104 & 104 & 104 & 104 \\
\hline
\end{tabular}

$\mathrm{n}=53$

Mean age $(\overline{\mathbf{x}})=59.45$

S.D. $=14.798$

2 eyes had cataract extraction surgery.

*excludes 1 anterior polar cataract.

$\dagger$ small pupils prevent accurate grading.

The number of ASC in the absence of PSC was 8 out of a total of 12 ASCs. 
lamp to view their pupils dilated with cyclopentolate $1 \%$ drops and phenylephrine $10 \%$ drops. These were instilled twice to obtain an 8 millimetre diameter pupil.

Lens opacities present were classified and graded according to the Oxford Clinical Cataract Classification and Grading System. ${ }^{7,8}$ Briefly, the crystalline lens is divided into the nucleus and cortex. The nucleus is defined as that amount of lens matter present at birth. Nuclear features graded Nuclear Brunnescence (NB) which is brown discolouration of the nucleus, and Nuclear White Scatter (WS).

Cortical features graded included thickness of the anterior clear zone (TH), anterior subcapsular opacities (ASC), cortical spokes (CS), waterclefts (WC), vacuoles (Vac), retrodots (RD), posterior subcapsular opacities (PSC) and focal dots (FD).

Nuclear and cortical features were graded from 0 to $\mathrm{V}$ except nuclear white scatter (I to $\mathrm{V})$. The observer compared the slitlamp view with standard charts and diagrams mounted on top of the lamp. These standard plates take into account the magnification used in the lamp. Only one of us (CSCL) graded the lens opacities.

A ? mark was placed instead of a grade when it was not possible to grade a feature such as cortical spokes in the absence of a well dilated pupil, or when it was impossible to judge the presence of a PSC in the presence of a dense nuclear brunescence. Any other features observed but not graded were noted, eg polar cataract.

An "en face" view of each lens was photographed onto Kodak Tri-X film with the "Oxford" Retro-Illumination Cataract Camera (Holofax Limited, Netherwood Road, Rotherwas, Hereford, HR2 6JZ, United Kingdom).

\section{Results}

Three patients did not have their lenses photographed. Three had small pupils despite dilating drops.

\section{Predisposing factors:}

None of the patients were diabetic. None had renal failure, although three patients had had nephrectomy for non malignant conditions.
One patient had an episode of amoebic dysentery and had been a prisoner of war and suffered severe malnutrition. One other patient had had a bad bout of diarrhoea whilst in Bangladesh. Eighteen patients had cardiovascular disease which includes hypertension, cerebrovascular accident and myocardial infarction.

Three patients had a positive family history of cataract (parents or sibs only). One patient had had radiation therapy to his trunk for testicular carcinoma when he was 14 years old.

Eight patients were on nifedipine and eight on non-steroidal anti-inflammatory drugs. None had systemic steroids, though one had intra-articular steroid injection and one possibly had steroid eye drops for five weeks when he was treated for "allergic eye disease".

Two patients had well controlled chronic open angle glaucoma and were not taking pilocarpine drops. Two patients had had unilateral cataract extractions. One patient had active bilateral anterior uveitis and he received treatment for that condition. One patient had unilateral viral keratitis. None of the patients had ocular trauma more severe than corneal foreign bodies. There were five myopes.

\section{Occupation and Ultraviolet Radiation}

None had exposure to artificial sources of ultraviolet (UV) irradiation. Eighteen patients thought their work was exclusively or mainly outdoors (OD) and 27 thought their work was exclusively or mainly indoors (ID). Eight thought their work was evenly distributed between outdoors and indoors.

The overall results are summarised in Table II. Data obtained from patients whose occupation is predominantly outdoors and indoors are sumarised in Table IVa and IVb. Data obtained from patients under the age of 55 years are summarised in Table $V$. The lens status of patients who had taken Allopurinol for five years or less and those who had taken the drug for over five years are summarised in Table VIa and VIb respectively. Table VII compares the overall cumulative results with that of the five subgroups. 


\section{Discussion}

In our group of patients on long term Allopurinol we have been able to document morphological changes in the lens and demonstrate these with photographs.

The unusual finding in our series of patients is the relatively high incidence of thinning of the anterior clear zone of the lens. Twenty five percent of our patients showed this change. Nineteen point four per cent of the patients in the age group below 55 years showed similar thinning of the anterior clear zone.

It is known that there is an association between the development of anterior subcapsular cataract and thinning of the anterior clear zone. ${ }^{9}$ We found a high incidence $(11.7 \%)$ of all our patients showed anterior subcapsular opacities.

An additional finding was that the anterior

Table IVa 'Outdoors' results

Number of eyes with a particular graded feature

\begin{tabular}{|c|c|c|c|c|c|c|c|c|c|c|}
\hline $\begin{array}{l}\text { Class } \\
\text { Grade }\end{array}$ & Th & ASC & CS & WC & Vac & RD & PSC & FD & NB & WS \\
\hline 0 & 0 & 30 & 19 & 31 & 21 & 21 & 28 & 11 & 1 & N/A \\
\hline I & 3 & $3^{*}$ & 12 & 2 & 14 & 9 & 7 & 7 & 12 & 0 \\
\hline II & 11 & 0 & 2 & 0 & 0 & 5 & 0 & 7 & 19 & 1 \\
\hline III & 16 & 1 & 0 & 0 & 0 & 0 & 0 & 7 & 3 & 11 \\
\hline IV & 3 & 0 & 0 & 0 & 0 & 0 & 0 & 3 & 0 & 12 \\
\hline V & 2 & 0 & 0 & 0 & 0 & 0 & 0 & 0 & 0 & 11 \\
\hline$?$ & $\begin{array}{c}0 \\
(\mathrm{O} \& \mathrm{I})\end{array}$ & 0 & 2 & 2 & 0 & 0 & 0 & 0 & $\begin{array}{c}0 \\
(\mathrm{II}-\mathrm{V})\end{array}$ & 0 \\
\hline Cumulative & 3 & 4 & 14 & 2 & 14 & 14 & 7 & 24 & 22 & N/A \\
\hline Total & 35 & $34^{*}$ & 35 & 35 & 35 & 35 & 35 & 35 & 35 & 35 \\
\hline
\end{tabular}

$\mathrm{n}=18$

$(\overline{\mathrm{x}})=62.56$ years

S.D. $=16.73$

1 eye had cataract extraction surgery.

*see Table I.

The number of ASC in the absence of PSC was 3 out of a total of 4 ASCs.

Table IVb 'Indoors' results

Number of eyes with a particular graded feature

\begin{tabular}{lcccccccccc}
\hline Class & & & & & & & & & \\
Grade & Th & ASC & CS & WC & Vac & RD & PSC & FD & NB & WS \\
0 & 0 & 48 & 28 & 44 & 32 & 37 & 51 & 17 & 2 & N/A \\
I & 17 & 2 & 20 & 10 & 21 & 12 & 1 & 19 & 27 & 0 \\
II & 14 & 1 & 6 & 0 & 1 & 1 & 0 & 10 & 23 & 9 \\
III & 19 & 1 & 0 & 0 & 0 & 1 & 0 & 6 & 0 & 13 \\
IV & 4 & 0 & 0 & 0 & 0 & 1 & 0 & 2 & 0 & 11 \\
V & 0 & 0 & 0 & 0 & 0 & 0 & 0 & 0 & 0 & 19 \\
$?$ & 0 & 2 & 0 & 0 & 0 & 2 & 2 & 0 & 2 & 2 \\
Cumulative & $($ O\&I $)$ & & & & & & & & & \\
Total & 54 & 54 & 54 & 54 & 54 & 54 & 54 & 54 & 54 & 54 \\
\hline
\end{tabular}

$\mathrm{n}=27$

$(\overline{\mathrm{x}})=57.78$ years

S.D. $=13.68$

The number of ASC in the absence of PSC was 4 out of a total of 4 ASCs. 
subcapsular changes were not usually accompanied by posterior subcapsular opacities. Generally, it is more common for posterior subcapsular changes to precede anterior subcapsular changes.

We would agree then with Fraunfelder's findings of the development of anterior subcapsular opacity in the relative absence of accompanying posterior subcapsular opacity in patients on Allopurinol therapy. In our series the associated posterior subcapsular changes were particularly low. This may reflect the low levels of sunshine and therefore ultraviolet light in England. The posterior subcapsular changes that we did note were almost all in the outdoor group. (Table VII).

There is some evidence that the anterior

Table V Young patients (under age of 55 years)

Number of eyes with a particular graded feature

\begin{tabular}{|c|c|c|c|c|c|c|c|c|c|c|}
\hline \multicolumn{11}{|l|}{ Class } \\
\hline 0 & 0 & 25 & 28 & 31 & 17 & 26 & 26 & 9 & 3 & N/A \\
\hline I & 6 & 3 & 3 & 0 & 14 & 5 & 3 & 11 & 24 & 0 \\
\hline II & 7 & 0 & 0 & 0 & 0 & 0 & 0 & 6 & 2 & 9 \\
\hline III & 17 & 0 & 0 & 0 & 0 & 0 & 0 & 3 & 0 & 13 \\
\hline IV & 1 & 0 & 0 & 0 & 0 & 0 & 0 & 2 & 0 & 7 \\
\hline V & 0 & 0 & 0 & 0 & 0 & 0 & 0 & 0 & 0 & 0 \\
\hline$?$ & $\begin{array}{c}0 \\
(\mathrm{O} \& \mathrm{I})\end{array}$ & 2 & 0 & 0 & 0 & 0 & 2 & 0 & $\begin{array}{c}2 \\
(\mathrm{II}-\mathrm{V})\end{array}$ & 2 \\
\hline Cumulative & 6 & 3 & 3 & 0 & 14 & 5 & 3 & 22 & 2 & N/A \\
\hline Total & 31 & $30^{*}$ & 31 & 31 & 31 & 31 & 31 & 31 & 31 & 31 \\
\hline
\end{tabular}

$\mathrm{n}=16$

$(\overline{\mathrm{x}})=40.19$ years

S.D. $=6.71$

1 eye had cataract extraction surgery.

* See Table I.

The number of ASC in the absence of PSC was 3 out of a total of 3 ASCs.

Table VIa 5 years or less of Allopurinol treatment

Number of eyes with a particular graded feature

\begin{tabular}{|c|c|c|c|c|c|c|c|c|c|c|}
\hline \multicolumn{11}{|l|}{ Class } \\
\hline 0 & 0 & 48 & 31 & 47 & 27 & 39 & 47 & 16 & 3 & N/A \\
\hline I & 8 & 4 & 20 & 4 & 27 & 8 & 7 & 18 & 28 & 0 \\
\hline II & 13 & 1 & 1 & 1 & 0 & 4 & 0 & 11 & 23 & 8 \\
\hline III & 23 & 1 & 0 & 0 & 0 & 1 & 0 & 8 & 0 & 17 \\
\hline IV & 9 & 0 & 0 & 0 & 0 & 1 & 0 & 1 & 0 & 14 \\
\hline V & 1 & 0 & 0 & 0 & 0 & 0 & 0 & 0 & 0 & 15 \\
\hline$?$ & $\begin{array}{c}0 \\
(\mathrm{O} \& \mathrm{I})\end{array}$ & 0 & 2 & 2 & 0 & 1 & 0 & 0 & $\begin{array}{c}0 \\
\text { (II-V) }\end{array}$ & 0 \\
\hline Cumulative & 8 & 6 & 21 & 5 & 27 & 14 & 7 & 38 & 23 & N/A \\
\hline Total & 54 & 54 & 54 & 54 & 54 & 54 & 54 & 54 & 54 & 54 \\
\hline
\end{tabular}

$\mathrm{n}=28$

$(\overline{\mathbf{x}})=55.93$ years

S.D. $=18.19$

2 patients had had unilateral cataract extraction surgery.

The number of ASC in the absence of PSC was 5 out of a total of 6 ASCs. 
subcapsular changes are dose related. Increased thinning was present in 36 patients who had taken the drug for more than 5 years compared to 11 patients with changes who had taken Allopurinol for less than five years. However, the incidence of anterior subcapsular opacity was the same in the two groups. (Table VII).

There is no definite evidence that Allopurinol produces a specific cataractogenic effect. We conclude however, that unusual morphological changes occur in the lens in patients with gout who have been treated with Allopurinol. It is possible that accompanying high levels of sunshine may cause additional posterior capsular changes. The further possibility that the changes are associated with the underlying disease, although unlikely, has not been excluded.

We should like to thank Mr A. Shun-Shin FRCS and Mr J. Sparrow FRCS for their helpful advice. We should also like to thank Mr T. Dawson of Holofax Limited for allowing us the use of an "Oxford" RetroIllumination Cataract Camera.

\section{References}

${ }^{1}$ Cameron JS and Simmonds HA: Use and abuse of Allopurinol. Br Med J 1987 294: 1504-5.

${ }^{2}$ Cameron JS and Simmonds HA: Correction: Use and Abuse of Allopurinol. Br Med J 1987 295: 350 .

${ }^{3}$ Fraunfelder FT, Hanna C, Dreis MW, Cosgrove KW Jr: Cataracts associated with Allopurinol

Table VIb Over 5 years of Allopurinol treatment

Number of eyes with a particular graded feature

\begin{tabular}{|c|c|c|c|c|c|c|c|c|c|c|}
\hline \multicolumn{11}{|l|}{ Class } \\
\hline 0 & 1 & 41 & 24 & 41 & 34 & 33 & 44 & 16 & 0 & N/A \\
\hline I & 17 & 5 & 16 & 9 & 15 & 13 & 3 & 13 & 20 & 0 \\
\hline II & 15 & 0 & 9 & 0 & 1 & 2 & 0 & 11 & 25 & 5 \\
\hline III & 17 & 1 & 1 & 0 & 0 & 0 & 1 & 6 & 3 & 11 \\
\hline IV & 0 & 0 & 0 & 0 & 0 & 0 & 0 & 4 & 0 & 10 \\
\hline V & 0 & 0 & 0 & 0 & 0 & 0 & 0 & 0 & 0 & 22 \\
\hline$?$ & $\begin{array}{c}0 \\
(\mathrm{O} \& \mathrm{I})\end{array}$ & 2 & 0 & 0 & 0 & 2 & 2 & 0 & $\begin{array}{c}2 \\
(\mathrm{II}-\mathrm{V})\end{array}$ & 2 \\
\hline Cumulative & 18 & 6 & 26 & 9 & 16 & 15 & 4 & 34 & 28 & N/A \\
\hline Total & 50 & $49^{*}$ & 50 & 50 & 50 & 50 & 50 & 50 & 50 & 50 \\
\hline
\end{tabular}

$\mathrm{n}=25$

$(\overline{\mathbf{x}}) \doteq 61$

S.D. $=14.92$

* see Table I.

The number of ASC in the absence of PSC was 3 out of a total of 6 ASCs.

Table VII Comparison of cumulative results of the population studied and the five subgroups (White Scatter omitted)

\begin{tabular}{lccrrrrrrrr}
\hline \multicolumn{10}{c}{ Number of eyes with } & \multicolumn{10}{c}{ particular feature (\%) } \\
\hline Class Subgroup & Th (0\&I) & ASC & \multicolumn{1}{c}{ CS } & WC & Vac & RD & PSC & FD & NB (II-V) & \\
Overall & 25.0 & 11.7 & 45.2 & 13.5 & 41.4 & 27.9 & 10.6 & 69.2 & 49.0 & $\mathrm{n}=53$ \\
Outdoors & 8.6 & 11.8 & 40.0 & 5.7 & 40.0 & 40.0 & 20.0 & 68.6 & 62.9 & $\mathrm{n}=18$ \\
Indoors & 31.5 & 7.4 & 48.2 & 18.5 & 42.6 & 27.8 & 1.9 & 68.5 & 42.6 & $\mathrm{n}=27$ \\
Young patients & 19.4 & 10.0 & 9.7 & 0 & 45.2 & 16.1 & 9.7 & 71.0 & 6.5 & $\mathrm{n}=16$ \\
$\leqslant 5$ years & 14.8 & 11.1 & 38.9 & 9.3 & 50.0 & 25.9 & 13.0 & 70.4 & 42.6 & $\mathrm{n}=28$ \\
$>5$ years & 36.0 & 12.2 & 52.0 & 18.0 & 32.0 & 30.0 & 8.0 & 68.0 & 56.0 & $\mathrm{n}=25$ \\
\hline
\end{tabular}


therapy. Am J Ophthalmol 1982 94: 137-209.

${ }^{4}$ Lerman S, Megaw JM, Gardner K: Allopurinol therapy and cataractogenesis in humans. Am J Ophthalmol 1982 94: 141-6.

${ }^{5}$ Lerman S, Megaw J, Fraunfelder FT: Further studies on Allopurinol therapy and human cataractogenesis. Am J Ophthalmol 1984, 97: 205-9.

${ }^{6}$ Harding JJ and van Heyningen R: Epidemiology and risk factors for Cataract. Eye 1987, 1: 537-41.
${ }^{7}$ Sparrow JM, Bron AJ, Brown NAP, Ayliffe W, Hill AR: The Oxford Clinical Cataract Classification and Grading System. Int Ophthalmol 1986, 9: 207-55.

${ }^{8}$ Brown NAP, Bron AJ, Ayliffe W, Sparrow J, Hill AR: The objective assessment of cataract. Eye 1987, 1: 234-46.

${ }^{9}$ Brown NAP and Tripathi R: Loss of the anterior subcapsular clear zone of the lens. Prognostic significance in cataract formation. Trans. Ophthalmol Soc UK. 1974, 74: 29-45. 